\title{
LES-CMC Simulations of Strong Swirling Confined Flames in a Model Gas Turbine Combustor
}

\author{
Pranit Gaikwad $^{1}$, S. Sreedhara ${ }^{1}$ \\ ${ }^{1}$ I. C. Engine and Combustion Lab, Department of Mechanical Engineering, \\ Indian Institute of Technology Bombay, Mumbai 400 076, India \\ pranit_gaikwad@iitb.ac.in; sreedhara.s@iitb.ac.in
}

\section{Extended Abstract}

In recent decades, gas turbine engines have been used extensively in prime movers and devices for power generation [1]. The stabilization of the flame has been attained in most gas turbine combustors using swirling flows. The reacting swirling flows in a combustor involves a complex interaction of the turbulent flow field with chemical reactions [2]. Due to financial requirements and technical challenges in the experiments, numerical investigation on this complex interaction has caught the attention of researchers.

High-fidelity numerical studies related to combustors involving swirling confined flames have been carried out continuously. The effects of confinement on premixed turbulent swirling flame have been studied by Nogenmyr et al. [3] by using large eddy simulation (LES). LES of a swirl-stabilized kerosene spray flame has been performed by Georg et al. [4] to study the performance of combustors. The non-premixed swirl-stabilized flames have been extensively studied using LES with advanced combustion models [5-8]. It may be observed in the literature that LES with conditional moment closure (CMC) model has capabilities to handle complex processes in the strong swirling flames [5, 8]. Hence, LES-CMC method may be used to predict complex interaction of the turbulent flow field with chemical reactions in gas turbine combustors.

In this work, Technische Flammen (TECFLAM) combustor [9] has been considered for numerical simulations using a three-dimensional (3D) LES-CMC approach. Several features and configurations of this combustor close to the gas turbines make it particularly suitable to study the complex phenomenon of the interaction between the flow and the chemistry. The TECFLAM combustion chamber consists of a central bluff-body, which is surrounded by a wide ring for the fuel (methane) and the swirled air inlets, and a water-cooled cylindrical chamber. More detailed configuration of the TECFLAM combustor may be found elsewhere $[9,10]$.

Formerly in our laboratory, the first-order CMC model was integrated with OpenFOAM (Open-source Field Operation And Manipulation) package called cmcFoam solver [11]. The solver allows the use of structured or unstructured mesh for the CMC grid with a parallelized algorithm and makes the code suitable for solving combustion problems in complex geometries. This solver was employed to study the structure of the non-premixed swirl-stabilized $\mathrm{CH}_{4} / \mathrm{H}_{2}$ flame using the RSM-CMC approach [12]. In the current study, LES and CMC calculations have been carried out using separate numerical grids (finer for LES and coarser for CMC) in order to reduce the computational effort. The coupling between LES and CMC has been achieved through filtered density and temperature in OpenFOAM using a script file. The strong swirling confined flames in the TECFLAM combustor, which develops from the interaction of a strongly swirling flow with fuel jets, has been studied. The numerical results predicted by LES-CMC code have been compared with measured data. The qualitative features of the flame (velocity, temperature and species concentrations) have been studied thoroughly.

\section{References}

[1] A. Di Gaeta, F. Reale, F. Chiariello, P. Massoli, "A dynamic model of a $100 \mathrm{~kW}$ micro gas turbine fuelled with natural gas and hydrogen blends and its application in a hybrid energy grid," Energy, vol. 129, pp. 299-320, 2017.

[2] E. Tsoutsanis, N. Meskin, "Dynamic performance simulation and control of gas turbines used for hybrid gas/wind energy applications," Appl. Therm. Eng., vol. 147, pp.122-142, 2019.

[3] K.J. Nogenmyr, H. J. Cao, C. K. Chan, R. K. Cheng, "Effects of confinement on premixed turbulent swirling flame using large Eddy simulation," Combust. Theory Model, vol. 17, no. 6, pp. 1003-1019, 2013. 
[4] G. Eckel, J. Grohmann, L. Cantu, N. Slavinskaya, T. Kathrotia, M. Rachner, P. L. Clercq, W. Meier, M. Aigner, "LES of a swirl-stabilized kerosene spray flame with a multi-component vaporization model and detailed chemistry," Combust. Flame, vol. 207, pp.134-152, 2019.

[5] Z. Huo, F. Salehi, S. Galindo-Lopez, M. J.Cleary, AR. Masri, "Sparse MMC-LES of a Sydney swirl flame," Proc Combust Inst, vol. 37, pp. 2191-8, 2019.

[6] N. Ansari, P. Pisciuneri, P. Strakey, P. Givi, "Scalar-Filtered Mass-Density-Function Simulation of Swirling Reacting Flows on Unstructured Grids," AIAA J, vol. 50, pp. 2476-82. 2012.

[7] H. Zhang, E. Mastorakos, "Modelling local extinction in Sydney swirling non-premixed flames with LES/CMC, Proc. Combust. Inst., vol. 36, pp.1669-76, 2017.

[8] S. Ayache, E. Mastorakos, "Investigation of the "TECFLAM" non-premixed flame using large eddy simulation and proper orthogonal decomposition," Flow Turbulence Combust, vol. 90, no. 2, pp. 219-241, 2013.

[9] P. Schmittel, B. Günther, B. Lenze, W. Leuckel, H. Bockhorn, "Turbulent swirling flames: Experimental investigation of the flow field and formation of nitrogen oxide," Proc. Combust. Inst., vol. 28, no. 1, pp.303-309, 2000.

[10] O. Keck, W. Meier, W. Stricker, M. Aigner, "Establishment of a confined swirling natural gas/air flame as a standard flame: Temperature and species distributions from laser Raman measurements," Combust. Sci. Tech., vol. 174, no. 8, pp.117-151, 2002.

[11] P. Gaikwad, S. Sreedhara, "OpenFOAM based Conditional Moment Closure (CMC) model for solving non-premixed turbulent combustion: Integration and validation," Comp. Fluids, vol. 190, pp. 362-373, 2019.

[12] P. Gaikwad, S. Sreedhara, "Prediction of a swirl-stabilized $\mathrm{CH}_{4} / \mathrm{H}_{2}$ flame structure using Conditional Moment Closure coupled with OpenFOAM", Energy Fuels., vol. 34, no. 2, pp. 2376-2384, 2020. 